\title{
The Effects of Applying the Problem-Based Learning (PBL) Theory on the 11th Grade Scientific Stream Students' Acquisition of the Concepts of Physics and the Development of Their Critical Thinking Skills
}

\author{
Sami Salameh Almasarweh ${ }^{1} \&$ Mohammad Khudairat ${ }^{1}$ \\ ${ }^{1}$ Isra University, Amman, Jordan \\ Received: January 5, 2021 \\ doi:10.5539/ass.v17n3p60 \\ Accepted: February 2, 2021 \\ Online Published: February 28, 2021 \\ URL: https://doi.org/10.5539/ass.v17n3p60
}

\begin{abstract}
The current study explores the effects of applying the Problem-Based Learning (PBL) Strategy on the 11th-grade scientific stream Jordanian students' acquisition of the concepts of developing their critical thinking skills. This study's significance lies in its emphasis on the worldwide growing tendency to apply PBL teaching strategies that consider developing the students' mental capabilities and creative thinking skills and, consequently, help them solve status-de- facto educational problems face and solve problems in their lives. The researchers used the experimental method in their study, which is based on studying the relationship between the independent and the dependent variables. For this reason, three study student groups, equal in their age, intelligence, academic achievement, social and economic standing, were selected. Two experimental groups were exposed to the independent variable (PBL) method, whereas the third control group was not exposed to the independent variable. Instead, it was taught in the Motion Unit in Physics by using the traditional teaching method. The results of the study were analyzed statistically, applying for the SPSS program. The Arithmetic Mean, the Standard Deviation, the Torsional Modulus, and the T-Test were used for the study analysis. The study results revealed that the two (PBL) experimental groups have proved to be much more superior to the control group's third traditional teaching method.
\end{abstract}

Keywords: problem-based learning (PBL), concepts in physics, critical thinking

\section{Introduction}

The Science of Physics is considered one of the most vital sciences that man has studied. It is also called the Science of Nature due to all its branches' connection with the various phenomena taking place in the universe. Physics as science provides man with detailed and accurate marvelous explanations of these natural phenomena, including cause and effect steps and interactions. The importance of physics comes up with the numerous applications made available for man. Such applications have turned to be indispensable necessities in our lives and have contributed to creating a massive cognitive and technological revolution that enabled man to adopt an easier lifestyle to carry out his daily activities.

In recent decades, critical thinking has become a major focus of educators' studies, who consider it one important guarantee for effective cognitive development, permitting individuals to use their maximum mental powers to interact positively with their environment. Several educational experts' research is directed towards the development of creative thinking skills as opposdevelopingive traditional memorization method (Al-Mani', 1996).

Within the Structuralism Theory framework and its intellectual foundations to create efficient learning, numerous studies have been conducted to examine the effectiveness and results of Structuralism-based learning strategies aimed at improving students' learning capabilities in various subjects. Among such strategies is Problem-Based Learning (PBL), which has been proved by some studies to significantly improve the students' critical thinking skills (Yaqoubi, 2010).

The (PBL) strategy focuses on the real problem- based learning. This requires the learner to approach the problems in various ways, either verbally or in writing. Another positive aspect of this strategy is that it splits the learning class into smaller cooperative groups, members who can all participate in voicing various views (Al-Shahrani, 2010).

In a world currently witnessing a massive cognitive revolution, it has become indispensable to implement 
contemporary teaching strategies contributing to improving the students' mental capabilities and superior thinking skills. At present, many teaching strategies can be used in teaching physics to provide incentives and motivation for students' learning achievement and help develop their thinking skills. In the light of the aforementioned, the two researchers have chosen to adopt the Problem-Based Learning (PBL) Strategy, with its many advantages, as the focus of this study.

\subsection{The Problem of the Study}

Despite recent developments in learning strategies, many teachers in educational institutions still use traditional methods. This is mainly attributed to their lack of knowledge about these contemporary learning strategies and their inability to apply them to promote the students' superior thinking capabilities (Al- Abdul-Aziz et al., 2017).

Although several problem-solving strategies are available nowadays, the (PBL) strategy remains the most effective to attain set-up goals. With its three-phase content constituents, namely the tasks, small cooperative groups, and the learner's sharing element, this (PBL) strategy presents the learning content in the form of educational tasks that stimulate thinking, reflect the basic concepts, and augment the learner' self-confidence for discussion (Zeitoun, 2007).

The (PBL) learning is considered a sort of student-centered reflection-based learning that assigns the classroom's active role to the students to solve life-related problems by following certain procedures (Robert Delisle, 2001).

The relationship between critical thinking and PBL Strategy can be illustrated in that PBL as a teaching method based on application. In the same way, critical thinking and the logic of scientific thinking involve the logic of behavior and ethical conduct, including self-criticism and respect for other peoples' opinions. It is worth noting that each phase of (PBL) affirms the critical thinking characteristics.

The researchers assume that due to the continued development of knowledge and the modern civilizational achievements, the teachers are requested to solve educational problems, using their experience for curriculum development and modern teaching methods application.

The researchers have conducted interviews with a sample of teachers to discuss the teaching methods they use and some non-traditional teaching methods. All interviewed teachers affirmed the urgent need to study modern teaching methods and strategies and apply them to cope with the massive scientific progress in information and modern technological developments. Based on the information above, the problem of the current study has been identified in the answers to the following questions:

1) What are the effects of applying the Problem- Based Learning (PBL) Strategy on 11th grade, scientific stream, Karak Governorate students' acquisition of the concepts of Physics and the development of their critical thinking skills?

2) What are the specific critical thinking skills intended to develop the $11^{\text {th }}$-grade students' sample using the (PBL) theory?

3) Are there any statistically significant differences in the average test results between the (PBL) Experimental Group and the traditional method Control Group, both of which studied and took the test in the Motion Unit in Physics?

\subsection{Significance of the Study}

1) Helping Physics teachers to develop teaching methods as per the (PBL) strategy guidelines.

2) Increasing the active and positive role of the students in the classroom.

3) Identifying the critical thinking level of the students by physics teachers

4) The Curriculum Department at the Ministry of Education can benefit from this study's results to reinforce the critical thinking skills in Physics at schools.

5) Helping the students solve status-de- facto educational problems, thus providing them with the skills to solve real-life situations.

\subsection{Objectives of the Study}

1) Identifying the effects of applying the Problem-Based Learning (PBL) Strategy on 11th Grade Students' acquisition of Physics concepts.

2) Identifying the effects of applying the Problem-Based Learning (PBL) Strategy on developing the students' critical thinking. 


\subsection{The Study Hypotheses}

1) There are statistically significant differences in the average test results between the 11th-grade scientific stream (PBL) First Experimental Group, who studied the Motion Unit in Physics, and the Traditional Method Control Group, who studied the same unit. The results have shown that the (PBL) Experimental Group is more superior.

2) There are statistically significant differences in the average test results between the 11th-grade scientific stream (PBL) Second Experimental Group, who studied the Motion Unit in Physics, and the Traditional Method Control Group, who studied the same unit. The results have shown that the second (PBL) Experimental Group is more superior.

3) There are statistically significant differences in the average test results between the 11th-grade scientific stream (PBL) First Experimental Group and the 11th-grade scientific stream Second Experimental Group in the critical thinking pre-test and post-test applications. The post-test application results have proved to be higher.

4) Statistically significant differences in the critical thinking average test results do not exist as per the gender variable.

\subsection{Limitations of the Study}

1) Material: The Motion Unit in the 11 Grade Physics Book, scientific stream as the unit's content fits the nature of the (PBL) strategy.

2) Sample: 11th-grade students, Scientific Stream.

3) Spatial Limitations: Qasr Female High School and Abdul- Wahhab Al- Majali Male High School in Qasr, Karak Governorate.

4) Temporal Limitations: The First Semester, 2018/2019.

\subsection{Study Terminology}

\subsubsection{Critical Thinking:}

Huitt, 1988 (as referred to in Al- Otoom, Jarrah, and Bishara, 2011) defines Critical Thinking as the ability to analyze facts, develop and organize ideas, identify opinions, make comparisons, solve problems and reach conclusions. In this study, Critical Thinking is defined as contemplative thinking governed by logic, analysis, deduction, and evaluation of discussions in a logical method that absorbs the relationship among concepts in the study.

\subsubsection{The (PBL) Strategy}

(Wheatly, 1991) has defined (PBL) as "a kind of learning that helps learners to comprehend what they have learned, build up a corresponding meaning and level up confidence in their abilities to solve problems. (Abu Zeina 2011) has labeled (PBL) as a teaching strategy based on designing study units touching on several real problems of interest to the students, consequently stimulating their thinking to solve these problems and gain new concepts, facts, and knowledge.

This study (PBL) is defined as a teaching strategy that can be implemented in three subsequent phases: the tasks, the cooperative groups, and sharing. The students can deepen their knowledge of the subject by sharing in the discussion to figure out the task solution. This strategy creates an environment of excitement and joy for the learners and strengthens their capabilities in practicing critical thinking. This model can be achieved by categorizing students into heterogeneous groups.

\section{Theoretical Framework and Previous Studies}

\subsection{Theoretical Framework}

\subsubsection{The (PBL) Strategy}

The current study focuses on Grayson Wheatly's model, which is considered one of the strongest advocates of the Structuralism Theory in modern times. Wheatly is a professor of mathematics at Florida University. In thirty years, he has authored more than a hundred books and articles in math teaching and PBL- based lesson plans, which considerably upgraded students' math learning and teaching. Wheatly has applied his Structuralism Model in teaching both math and science classes.

The PBL strategy is considered one of the teaching strategies that emerged from the Structuralist Theory's thought. Wheatly's approach is based on implementing the Structural Theory ideas in teaching math and science. 
The learners can create interrelated meaningful concepts when he/she is exposed to problems in small cooperative groups. The PBL strategy is composed of three phases: The Tasks, the Cooperative Groups, and Sharing, all of which will be discussed in depth later.

In recent years, educators have expressed their concern over students' inability to apply critical thinking. For instance, (Cartina et al., 1999) stated that the US National Report had pointed out that most of the 17-year- old students in the US could not apply the superior mental processes. Only one out of five students could write a convincing article, and one out of three could solve multiple-step math problems.

In light of the discussion above, the researchers think that the PBL Strategy is considered one of the most important strategies in teaching Sciences in general and Physics in particular. It stimulates the learners' critical thinking skills, reactivates previously-stored knowledge in them, and reconstruct this knowledge to be employed to correlate with new givings.

\subsubsection{Reasons for Adopting the PBL Strategy}

The PBL Strategy is considered superior to the traditional method for the following reasons:

1) The learners can retain a little of what they have learned in the traditional method.

2) The learners usually do not apply the knowledge in the correct scientific way in the traditional method.

3) The learners tend to forget a lot of what they have learned in the traditional method.

4) The three-phase PBL strategy helps learners employ previous knowledge and skills in various emerging life situations because it helps retrieve, reactivate, and reconstruct previous knowledge to fit with the newly-acquired experience (Dempsey, 2000).

According to (Hujaily, 2011), the PBL Strategy is characterized by designing meaningful problem-based lesson plans, by means of which the learners can get trained in research skills, develop cooperative work skills, acquire a sense of responsibility, and increase self- activation. It should be noted here that the teacher plays the role of a facilitator only.

\subsubsection{The PBL Strategy Constituents (Wheatly Model)}

(Wheatly et al., 1991, p. 3) mentioned that the formation of the PBL model was largely affected by the math science teaching standards and the structuralist Glaser Field's ideas. According to Wheatly, the mathematical knowledge cannot be transferred, but rather can be formulated and built up by the learner. Every learner has his own experience in the process of knowledge formulation and builds up. However, each learner acquires an accumulation of other people's experiences as well. Learning can be attained both individually and collectively. The PBL model is composed of three main basic elements: The Tasks, The Cooperative Groups, and Sharing.

\subsubsection{First: Learning Tasks}

The Learning Tasks lay the foundations for the PBL strategy, and the proper and accurate selection of these tasks is the parameter for the success or failure of this strategy. For the success of this strategy, the selected learning tasks, as summarized by (Al- Huthaifi, 2002, pp. 142-143), must adhere to the following:

1) Simple, not complicated.

2) Direct the learners to free search to set up hypotheses and multiple solutions.

3) Encourage learners to make decisions.

4) Encourage the learners to ask the type of questions, such as What If ......?

5) Allow for discussion, dialogue, and communication.

6) Must be interesting and attractive.

\subsubsection{Second: The Cooperative Groups}

To apply the principle of cooperative learning, the learners are sub-divided into smaller groups of (3-6) students each. The students in each group should have heterogeneous study achievement levels. This division is based on its score in one of the achievement tests. They work together to plan or put forward a proper solution to the problem. They could also change roles, and their teacher is not far away, but he is in a sense a member in each group (Al- Shahrani, 2010, p. 51).

\subsubsection{Third: Sharing}

This is the third phase in Wheatly's Model, where all cooperative groups take part, and the teacher leads the groups to discuss the solutions proposed by the leaners, evaluate them, and put them in their known respective 
scientific outcome (Abdul-Jaleel, 2000).

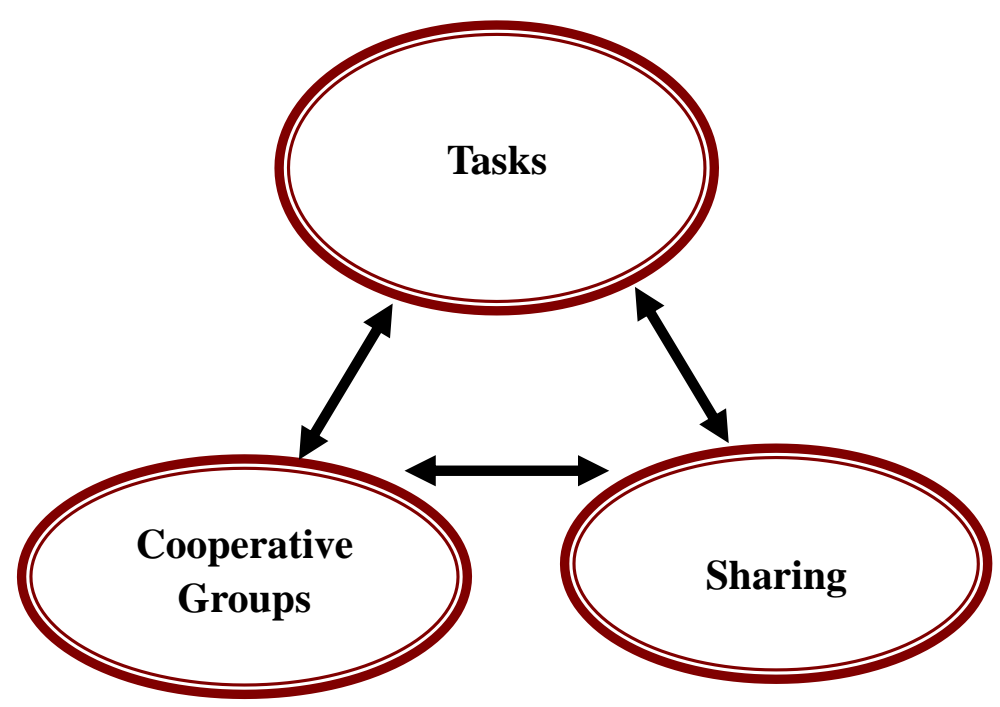

Figure 1. Model Constituents of the PBL Strategy

2.1.4 The Progress of Learning in the PBL Strategy Takes the Following Steps:

1) Identifying learner's pre-knowledge.

2) Distributing tasks to the learners after dividing them into sub-groups.

3) The teacher's role is restricted to walking around in the classroom, watching students, and initiating dialogues.

4) Before the end of the session, each group presents its proposed outcomes and explanations to the problems (Al-Najdi et al.).

The significance of this strategy stems from creating problematic real-life situations for learners. Such an environment helps the learners achieve cognitive equilibrium to mental activity, leading to creative or actual solutions. This PBL strategy can also open the door to exploring a wide range of ideas, some of which can be effectively employed to solve future problems. Moreover, the PBL Strategy creates an atmosphere of interest, joy, and curiosity for the learners (Snyder, 2008).

\subsection{Previous Studies}

The researchers reviewed some studies, as follows:

Al-Ghamdi's study (2019) aimed at identifying the impact of a self-organized problem-centered learning strategy on developing academic achievement and self-regulation in jurisprudence among high school students in the Kingdom of Saudi Arabia, and the researcher used the experimental approach according to the pre-and post-design of the two research groups (experimental and control), the research sample consisted of (60) students randomly selected from the first-grade secondary school students, and they were distributed randomly and equally among the two research groups so that each group consisted of (30) students, and the researcher prepared a guide for the teacher to teach three units in the subject of jurisprudence: felonies, retribution, Dates) according to the self-organized problem-centered learning strategy, and the tools were identified in: a test of academic achievement in the subject of jurisprudence, and a measure of self-organized learning strategies, and the study reached the effectiveness of a learning strategy centered around the self-organized problem.

As for the study of Shihab and Jasim (2018), it aimed to identify the effect of the problem-centered learning method according to mental flexibility (automatic - adaptive) in teaching the skill of the Arab jump on the mat of ground movements in the artistic gymnastics of the research sample, and to identify the best four groups in learning some skills Kinetic in learning the skill of the Arab jump on the carpet of ground movements in your artistic gymnastics, The two researchers used the experimental method by designing the four groups, the pre and post-test on a sample of the 48 third-grade students of two divisions, where each group was divided into two groups according to the scale of mental flexibility (Two experimental groups (those with automatic cognitive 
flexibility - adaptive) and two control groups (those with mechanical mental flexibility - adaptive), and after collecting data and treating them statistically, the two researchers concluded that the best groups learned the skill of the Arab jump, the experimental group, those with automatic mental flexibility, followed by those with adaptive cognitive flexibility, then the control group with automatic mental flexibility, followed by those with adaptive mental flexibility.

The study of Al-Masry (2017) aimed to demonstrate the effectiveness of problem-centered learning strategy in developing productive thinking among students of the basic sixth grade through the science curriculum. The study sample consisted of (105) male and female students, divided into two experimental and control groups equally at a rate of (35) students in each group; they were selected from the girls' Abasan Preparatory School and Bani Suhaila Preparatory School in Khan Yunis governorate. The two experimental groups studied the unit's topics (biological processes in plants) using problem-centered learning, while the control group studied the same topics in a common way of teaching. The researcher used the productive thinking test in two parts: the thinking test, the creative (Torrance) test, and the critical thinking test (prepared by the researcher). The researcher has adopted the quasi-experimental approach; the study results found statistically significant differences in favor of the students of the two experimental groups who studied the topics of (biological processes in plants) using the problem-centered learning strategy in testing productive thinking in favor of the dimensional application. The researcher recommended activating modern constructive strategies to teach the science curriculum and focus on learning methods that make the learner active in the educational site.

The study of Abu Hamad (2016) aimed to find out the effect of employing a problem-centered learning strategy on developing mathematical thinking skills among ninth-grade students in Gaza. The study tool used by the researcher is to test mathematical thinking skills; she applied it to a randomly selected sample of (64) students in the Bani Suhail Preparatory School for UNRWA so that two classes were chosen to represent the experimental group (32) students and the other to represent the control group (32) students during the academic year (2015-2016). The researcher used the experimental method in her study. The study found statistically significant differences at $(\alpha 0.05 \geq)$ between the mean scores of the experimental group students and the average of their peers from the control group in testing mathematical thinking skills for the benefit of the experimental group. The researcher recommended the necessity of using the learning strategy centered around The problem in teaching mathematics at all educational levels and holding training courses for mathematics teachers to teach them how to use problem-centered learning strategy in developing mathematical thinking.

Shahhat (2012) study aimed to identify the role of the PBL Strategy in the development of $5^{\text {th }}$-grade students' skills in science. It used the analytical- descriptive method and the semi-experimental method. The researcher set and used life skills tests. The study results have shown that the arithmetic mean of the grades of the experimental group is higher than the control group in the post-application test. This indicates that the PBL Strategy is more effective than the traditional method.

Al-Musa'di (2011) study aimed_at identifying the effects of the PBL Strategy on the $5^{\text {th }}$-grade students' study achievement in mathematics and their attitudes to study this course. The researchers used the experimental method in both the Experimental Group and Control Group. The sample has 59 randomly- selected students, 30 of them in the Experimental Group and 29 in the Control Group. The tools of the study included an achievement test and a math learning attitude index. The researchers used the following statistical methods: T-Test for two independent samples and two dependent samples, K2, Alpha Formula, and Spearman-Brown Formula. The study results have shown that the PBL Strategy has developed the students' math study achievement and motivations.

AL-Hasani (2011) entitled "PBL Strategy Effects on 8th-grade Female Students' Biology Study Achievement and Learning Processes" was conducted in Iraq to identify the effects of PBL Strategy on 8th-grade female students' biology achievement and learning processes. The sample has 64 students divided into an experimental group (34) and a control group (30). The researcher has used the experimental method and the T-Test as a statistical method. The study tools included an achievement test and a learning process index. The study results have revealed that the PBL Strategy is more effective in the students' study achievement and learning processes.

Yurick (2011) study aimed to identify the effects of using the PBL Strategy to teach concepts of internet-based Nano-Technology to primary school students and their attitudes to learn the General Sciences material. The researchers used the Control Group's experimental method and made them sit for a pre-study and a post-study test. The study tools were confined to the scientific concept test and an attitude index. The T-Test was used as a study tool to measure the differences in the groups' arithmetic mean under study. The study's most important results have shown statistically significant differences $(05.0 \geq \alpha)$ in the arithmetic mean of the Nano-Technology achievement test in favor of the PBL experimental group. Statistically, significant differences are also present 
$(05.0 \geq \alpha)$ in the arithmetic mean of the General Sciences attitude level in favor of the experimental group. The researcher has recommended using the PBL Strategy as an effective method for concept development.

Wesolowski (2008) study aimed to identify the effects of using the PBL Strategy to conduct internet-based biology lab experiments in remote areas. The study was conducted at Delaware University for major biology students. The study results have shown an improvement in the students' biology lab experiments conducting levels and critical thinking skills.

Bellgon (2010) study aimed to identify the effects of using the PBL Strategy to develop intermediate school Saudi Arabian female students' critical thinking skills in science. The researchers have used the experimental method to design the Control Group and have given them a pre-study test and a post-study test. The sample under study has (137) female students from the first intermediate and the third intermediate class. The study tool was restricted to a critical thinking test in science. The study results have shown tangible statistically significant differences $(05.0 \geq \alpha)$ in the arithmetic mean of the results of the critical thinking test in favor of the Experimental Group. The researchers have recommended the urgent need for in-service training for the sciences teachers to apply the PBL Strategy (Wheatly Model).

\section{Study Methodology}

In their study, the two researchers have used the experimental method, based on the study of the relationship between the independent and dependent variables. They tried their best to reduce the individual differences among the sample groups understudy to the minimum. Therefore, two study groups have been selected, equal in their members' age, intelligence, learning achievement level, and social and economic levels.

\subsection{The Study Population and Its Sample}

The study community is represented by all $11^{\text {th }}$-grade public schools' scientific stream students for the academic year 2018/2019 in the Al-Qasr area, Karak Governorate. The study samples were randomly selected from two schools: Al-Qasr Female High School and Abdul- Wahhab Al-Majali Male High School. The study sample's total number is (99), divided into two Experimental Groups and one Control Group, as seen in table No. 1. The two Experimental Groups studied the Motion Unit in physics, using the PBL Strategy, whereas the Control Group studied the same unit, using the traditional method.

Table 1. Number of students per group

\begin{tabular}{cc}
\hline Group & Number of Students \\
\hline First Experimental & $\underline{33}$ \\
Second Experimental & $\underline{33}$ \\
Control Group & $\underline{33}$ \\
Total Number & $\underline{99}$ \\
\hline
\end{tabular}

\subsection{The Statistical Treatment}

The results of the study were analyzed statistically using the SPSS program. The following statistical processors were used: The Arithmetic Mean, the Standard Deviation, the Torsional Modulus and the T-Test.

\subsection{The Study Procedures}

To answer the questions of the study, the following steps were followed:

First: Specifying the critical thinking skills needed for the $11^{\text {th }}$-grade scientific stream students in the Physics subject.

This can be done by:

1) Investigating some related literature about critical thinking and skills.

2) Studying the students' nature.

3) Preparing a list of essential skills of thinking in its final form.

Second: Preparing a student guide of the Motion Unit in Physics assigned for the 11grade students in the first Semester as per the guidelines of the PBL Strategy; this can be done by:

1) Investigating some practices, research papers, and studies related to the PBL Strategy.

2) Preparing the Teacher's Guide for the 11th-grade Physics material content as per the framework of the PBL Strategy. 
3) Referring to the teacher's Guide to the referees' committee and introducing the modifications based on their evaluation results.

4) Preparing the Teacher's Guide in its revised and final form.

Third: Preparing the Study tools, this can be done by

1) Designing the 11grade scientific stream Critical Thinking Skills Exam by the two researchers.

2) Referring to the Study Tool to referees and introducing the needed modifications in the light of their suggestions.

3) Exploratory experimentation of the approved Study tool on an 11grade student sample.

4) Drafting the Study Tool in its final form.

\section{Fourth: Field Experimentation}

This can be done by:

1) Selection of the sample individuals from the 11-grade students from two different schools, i.e., AbdulWahhab Al- Majali Male High School and Al- Qasr Female High School, Karak Governorate, and dividing them into three equal groups, one of which represents the Control Group, and the other two the Experimental Groups.

2) Study tool pre-application on the group under study.

3) Teaching the Experimental Groups using the PBL Strategy while teaching the Control Group using the traditional method.

4) Study tool post-application on the groups under study.

\subsection{Control of Variables}

The variables of the three groups under study have been controlled to_create homogeneous samples as follows:

1) Groupage: All students whose age is not between (16-17) have been excluded.

2) The social and economic standing: As the study was conducted in the Qaser area, Karak Governorate, and consisted of students more or less the same social and economic standing based on data from the schools' student records, this in itself is regarded as control of the students' social and economic factor, which proves the accuracy of the results of the study.

3) Critical Thinking: To verify this variant, the three groups under study (two experimental and one control) were given a pre-study critical thinking test, which revealed no statistically significant differences in the arithmetic mean of the test results. This is a strong indicator that the three groups are similar in their critical thinking skills.

Table 2. Differences between the two experimental groups and the control group in the Arithmetic Mean of the critical thinking pre-study test results

\begin{tabular}{cccccccc}
\hline $\begin{array}{c}\text { Group under } \\
\text { Study }\end{array}$ & $\begin{array}{c}\text { Number of } \\
\text { Students }\end{array}$ & $\begin{array}{c}\text { Arithmetic } \\
\text { Mean }\end{array}$ & $\begin{array}{c}\text { Standard } \\
\text { Deviation }\end{array}$ & $\begin{array}{c}\text { Torsional } \\
\text { Modulus }\end{array}$ & $\begin{array}{c}\text { Sig. } \\
\text { Level }\end{array}$ & $\begin{array}{c}\text { T- } \\
\text { Value }\end{array}$ & Results \\
\hline $\begin{array}{c}\text { First } \\
\text { Experimental }\end{array}$ & 33 & 20.64 & 5.38 & -0.39 & .19 & -1.99 & NO \\
$\quad$ Control & 33 & 22.24 & 4.64 & -0.33 & & & Significant \\
$\quad \begin{array}{c}\text { Second } \\
\text { experimental }\end{array}$ & 33 & 21.67 & 3.99 & .110 & .59 & -0.54 & Statistical \\
Control & 33 & 23.88 & 4.64 & -0.33 & $\ldots$ & - & Differences \\
\hline
\end{tabular}

Modules and the T-Test

\section{Findings of the Study}

The critical thinking test results that the two experimental groups and the control group took will be put forward and analyzed in this paper to verify the degree of accuracy of its four hypotheses.

\subsection{Verification of the Accuracy of the First and Second Hypotheses}

The first hypothesis states that there are statistically significant differences between the first experimental and second experimental groups' critical thinking test results. Similarly, the second hypothesis states that there are statistically significant differences between the arithmetic mean of the critical thinking test in the results of the 
second experimental group and the control group in favor of the second experimental group.

Table 3. Differences between the two experimental groups and the control group in the Arithmetic Mean of the critical thinking post-study test results

\begin{tabular}{cccccc}
\hline Group under Study & Number of Students & Arithmetic Mean & Standard Deviation & Sig. Level & Statistical difference \\
\hline First Experimental & 33 & 63.82 & 15.21 & 0.003 & 0.05 \\
Control & 33 & 64.03 & 13.18 & & 0.002 \\
Second experimental & 33 & 66.24 & 14.02 & 0.05 \\
Control & 33 & 64.03 & 13.18 & & \\
\hline
\end{tabular}

Table 3 has shown that statistically significant differences at (0.05) level exist between the two experimental groups applying the PBL Strategy and those of the traditional method control group in the critical thinking post-application test designed for this purpose. The superior experimental groups' results are mainly attributed to the effects of the PBL Strategy. Accordingly, the first and second hypotheses of this study are accepted. This way, the current study results confirm with previous studies, such as Shahhat, 2012, Al- Musa'idi, 2011, AL- Hasani, 2011, Yurick 2011 and Wesolowski, 2008.

\subsection{Verification of the Accuracy of the Hypothesis}

This hypothesis states that statistically significant differences exist between the first and second experimental groups' arithmetic mean of the pre-study and post-study critical thinking test results in favor of the post- study test.

Table 4. Differences between the first and second experimental groups' arithmetic mean in the pre-study and post-study critical thinking test results

\begin{tabular}{|c|c|c|c|c|c|c|c|c|}
\hline \multirow[b]{2}{*}{ Group } & \multicolumn{3}{|c|}{ Post-Test } & \multicolumn{3}{|c|}{ Pre- Test } & \multirow[b]{2}{*}{$\begin{array}{l}\text { Sig. } \\
\text { Level }\end{array}$} & \multirow[b]{2}{*}{$\begin{array}{l}\text { Statistical } \\
\text { Level }\end{array}$} \\
\hline & $\begin{array}{l}\text { Number of } \\
\text { Students }\end{array}$ & $\begin{array}{l}\text { Arithmetic } \\
\text { Mean }\end{array}$ & $\begin{array}{l}\text { Standard } \\
\text { Deviation }\end{array}$ & $\begin{array}{c}\text { Number } \\
\text { of } \\
\text { students }\end{array}$ & $\begin{array}{l}\text { Arithmetic } \\
\text { Mean }\end{array}$ & $\begin{array}{l}\text { Standard } \\
\text { Deviation }\end{array}$ & & \\
\hline $\begin{array}{c}\text { First } \\
\text { Experimental }\end{array}$ & 33 & 63.82 & 15.21 & 33 & 20.64 & 5.38 & 0.004 & 0.05 \\
\hline $\begin{array}{c}\text { Second } \\
\text { experimental }\end{array}$ & 33 & 66.24 & 14.02 & 33 & 21.67 & 3.99 & 0.0002 & 0.05 \\
\hline
\end{tabular}

As shown in Table 4, statistically significant differences exist at (0.05) level exist in the post-study test compared to the pre-study test in favor of the two experimental groups, who studied the Motion Unit in Physics applying the PBL Strategy. All variables have been fixed to exclude their effect on the results. The difference in the pre-study and post-study results is mainly attributed to the strong effect of the PBL Strategy on the development of the sample groups' critical thinking skills. The PBL Strategy helps learners build up knowledge in social interaction environments, develop needed problem-solving skills, strengthen motivation to participate in scientific activities, and creates self-confidence to face and solve actual life situations. All of this conforms with several previous studies supporting the strong effect of the PBL Strategy. Therefore, the third hypothesis of this study has been accepted.

\subsection{Verification of the Accuracy of the Fourth Hypothesis}

The Fourth hypothesis states that no statistically significant differences exist in the critical thinking test results according to the learner's gender.

Table 5. Statistical differences in the results of the first and second experimental groups' critical thinking poststudy test

\begin{tabular}{cccccc}
\hline Group & $\begin{array}{c}\text { Number of } \\
\text { students }\end{array}$ & $\begin{array}{c}\text { Arithmetic } \\
\text { Mean }\end{array}$ & $\begin{array}{c}\text { Standard } \\
\text { Deviation }\end{array}$ & $\begin{array}{c}\text { Sig. } \\
\text { Level }\end{array}$ & $\begin{array}{c}\text { Statistical } \\
\text { Difference }\end{array}$ \\
\hline $\begin{array}{c}\text { First Experimental (Male) } \\
\text { Second Experimental } \\
\text { (Female) }\end{array}$ & 33 & 63.82 & 15.21 & 0.032 & 0.05 \\
& 33 & 66.24 & 14.02 & 0.032 & 0.05 \\
\hline
\end{tabular}

As seen in the Table 5, there are statistical differences at (0.05) level in the results of the critical thinking test 
according to the learner's gender (male and female students). Only slight differences have been calculated. Therefore, the fourth hypothesis has been accepted.

\section{Recommendations}

In light of the study results, the researchers recommend the following:

1. Adopting and applying this study results to obtain the maximum benefits from modern learning strategies in Physics.

2. Conducting further studies on the PBL Strategy and its role in multiple intelligence and deductive thinking.

\section{References}

Abdul- Jaleel, A. (2009). The effect of problem-centered learning strategy on generative thinking and the trend towards industrial security and occupational safety among industrial secondary school pupils. Presented to the third annual scientific conference of the College of Education in Port Said (School of the Future Reality and Hope), Egypt, Part 1.

Abdul-Aziz et al. (2017). The effect of the brainstorming strategy on the academic achievement of the teaching design subject for Al-Balqa University students. Journal of Sciences and Humanities, 28(1), 1-16.

Abu Hamad, K. (2016). The effect of employing problem-centered learning strategies on developing mathematical thinking skills among ninth-grade students in Gaza. Unpublished MA Thesis, College of Education, Islamic University, Gaza. Retrieved from https://iugspace.iugaza.edu.ps/bitstream/handle/20.500. 12358/19339/file_1.pdf?sequence=1\&isAllowed=y

Abu Zaina, F. (2011). The Investigative Model in Thinking and Problem Solving First Edition. Amman, Jordan: Wael House.

Al_shahrani, M. (2010). Using the Wheatley model in teaching mathematics on academic achievement and attitudes towards it among sixth-grade students. Unpublished Ph.D. thesis, College of Education, Umm Al-Qura University, Saudi Arabia.

Al_Ya'qoubi, A. (2010). A technical program employs a problem-centered learning strategy to develop systems thinking skills in science among ninth-graders in Gaza. Unpublished MA Thesis, College of Education, Islamic University, Gaza.

Al-Ghamdi, Y. (2019). The effect of the self-organized problem-centered learning strategy on academic achievement and self-regulation in jurisprudence among secondary school students. Umm Al-Qura University Journal of Educational and Psychological Sciences, 10(2), 279-311. Retrieved from http://search.mandumah.com/Record/971202

Alhasani, O. (2011). The Effectiveness of Teaching with a Learning Strategy Centered on the Problem in Achievement and Development of Science Processes for Intermediate Second Grade Students in Biology. Unpublished Master Thesis, College of Education, University of Al-Qadisiyah.

Al-Hujaili, M. (2011). The Effect of Teaching Mathematical Concepts Using Problem-Centered Learning Strategy on Achievement and Attitude Toward Mathematics for New Students in The Mathematics Department of The Teachers College in Madinah. The Journal of Reading and Knowledge, 116.

Al-Huthaifi, K. (2002). Effectiveness of problem-based education strategy in developing academic achievement and the trend towards science for middle school students. The Fifteenth Scientific Conference of the Egyptian Society for Curricula and Teaching Methods, (91), 169-123.

Al-Mani', A. (1996). Development of thinking abilities of pupils: A proposal to apply for the Cort program. The Arabian Gulf Message Issue, 59, 15-43.

Almasadi, A. (2011). The effect of using a problem-centered learning strategy on the mathematics achievement of fifth-grade students and their attitudes towards it. Anbar University Journal of Islamic Sciences, (3), 243-220.

Al-Masry, A. (2017). The effectiveness of a problem-centered learning strategy in developing productive thinking through the science curriculum. Palestine University Journal for Research and Studies, 7(2), 259-292. Retrieved from https://scholar.google.com/citations?user=cMPJmGYAAAAJ\&hl=en

Al-Najdi et al. (2005). Recent trends in science education in those with international standards, development of thinking and constructivist theories. Arab Thought House, Cairo. 
Al-Shahhat, D. (2012). The effectiveness of the problem-centered learning strategy in developing some life skills in science for fifth-grade pupils. Journal of the College of Education, Port Said University, 12.

Al-Utoom et al. (2011). Development of thinking skills, theoretical models, and practical applications (3rd ed.). Dar Al Masirah, Amman, Jordan.

Beljun, K. (2010). The Effectiveness of (Wheatley) Model of Problem-Centered Education in Developing Critical Thinking Skills for Middle School Students in the Subject of Science. Journal of Studies in Curricula and Teaching Methods, (164), 109-159.

Catrina, D., Therese, L., \& Renee, M. (1999). Improving Critical Thinking Skills in Secondary Math \& Social Studies Classes. Master's action research project, saint Xavier University.

Cobb et al. (1991). Assessment of Problem-Center Second -Grade Mathematics Project. Journal for Research in Mathematics Education, 22(1), 3-29.

Delisle, R. (2001). How to use problem-based learning in the classroom. Translation of Dhahran National Schools, Dar Al-Kitab Al-Tarabi for publishing and distribution.

Dempsey, T. L. (2000). Leadership for the Constructivist Classroom, Development of A Problem Based Learning Project. Ph.D. Dissertation, Miami University: The Graduate School.

Dobbs, V. (2008). Comparing Student Achievement in the Problem- Based learning Classroom and Traditional Teaching Methods Classroom. Ph.D. of Education Specialization in Teacher Leadership: Walden University.

Jarwan, F. (2013). Teaching thinking, concepts, and applications (6th ed.). Dar Al-Fikr, Amman, Jordan.

Shehab, G., \& Jasem, R. (2018). According to mental flexibility (automatic - adaptive), the effect of problem-centered education in learning the skill of the Arab jump on the device of ground movements mat in your artistic gymnastics for women. Journal of the College of Physical Education, University of Baghdad, 30(3), 230-245. Retrieved from https://search.emarefa.net/en/search?append=PERSON_FILTER_EN_NAME

Snyder, L. (2008). Teaching Critical Thinking and Problem-solving skills. The Delta Pi Epsilon Journal, 50(2), 90-99.

Wesolowski, M. (2008). Facilitating problem- based learning in an online biology laboratory course (Unpublished Master's Thesis). University Delaware, Doctoral Dissertation. Retrieved from http://reforma.fen.uchile.cl/Papers/Teaching\%20Critical\%20Thinking\%20Skills\%20and\%20problem\%20so lving\%20skills\%20-\%20Gueldenzoph,\%20Snyder.pdf

Wheatly, G. (1991). Constructivist Perspective on Science Mathematics Learning. Journal of Science Education, 75(1), 9 -21. Retrieved from https://onlinelibrary.wiley.com/doi/abs/10.1002/sce.3730750103

Yurick, K. A. (2011). Effects of Problem - Based Learning with Web-Anchored Instruction in Nano-technology on the Science Conceptual Understanding, the Attitude towards Science, and the Perception of Science in Society of Elementary Students. ProQuest LLC, Ed.D. Dissertation, Florida Atlantic University. Retrieved from https://eric.ed.gov/?id=EJ826495

Zaitoon, A. (2007). Constructivism Theory and Strategies for Teaching Science (1st ed.). Al-Shorouk Publishing and Distribution House, Amman.

\section{Copyrights}

Copyright for this article is retained by the author(s), with first publication rights granted to the journal.

This is an open-access article distributed under the terms and conditions of the Creative Commons Attribution license (http://creativecommons.org/licenses/by/4.0/). 